\title{
PENINGKATAN ADAPTASI COVID-19 DAN MODERASI BERAGAMA
}

\author{
Rayno Dwi Adityo \\ Fakultas Syariah, UIN Maulana Malik Ibrahim Malang \\ raynodwiadityo@uin-malang.ac.id
}

\begin{tabular}{l} 
Info Artikel \\
\hline Riwayat Artikel: \\
Diterima: Januari 2021 \\
Direvisi: Februari 2021 \\
Diterbitkan: Maret 2021 \\
\hline
\end{tabular}

\section{Keywords:}

Covid-19

Moderation

Empowerment

Adaptation

Improvement

\begin{abstract}
The Covid-19 pandemic does not seem to be over yet, the problems that arise are so many as a result of the epidemic, starting from the problem of the decline in the economic sector, limited community mobility so that the government always encourages to implement health protocols, starting from maintaining distance, avoiding crowds, always washing hands, carrying a hand sanitizer, and wearing a mask when traveling, are not only a pandemic problem but also the penetration of destructive religious ideas that tends to be radical so that it is again necessary to spread a moderate religious perspective. Through the Ministry of Religion of the Republic of Indonesia, the socialization of religious moderation has begun again. The purpose of carrying out this community service research is first, as a form of embodiment of the tri darma of higher education in the field of community service; second, so that people can improve their adaptation to the environment and conditions that are currently happening. The methods used are lectures, providing information, simulations and training within the framework of the Paticipatory Rural Apprasial. The results achieved were the implementation of socialization in the context of preventing Covid-19 by making posters, flyers, spandung, giving advice and education. In the religious moderation program, namely by inserting messages of peace in religion in educational institutions, TPQ, and Islamic boarding schools, but some are using virtual platforms. Economic and community empowerment program by reviving one of the local tourist sites in Dhompo village, Pasuruan Regency. Community needs program by producing an information technology-based village application product. The conclusion is that the more people can improve their adaptation in pandemic conditions, the hope is that they can improve safety and also change their habit patterns to stay productive.
\end{abstract}

Copyright (C) 2021 JRCE. All rights reserved.

\section{Korespondensi:}

Rayno Dwi Adityo, UIN Maulana Malik Ibrahim Malang, Jl. Gajayana No. 50 Malang, Jawa Timur, Indonesia 65144 raynodwiadityo@uin-malang.ac.id

\section{PENDAHULUAN}


51

Pandemi Covid-19 belum terlihat akan berakhir, pandemi bermula disekitar akhir tahun 2019 dari Cina tepatnya provinsi Wuhan, penyebarannya yang masif hampir di seluruh belahan dunia terpapar dan telah membawa dampak yang begitu hebat, perubahan-perubahan pola perilaku dipaksa untuk berubah demi menjaga kelangsungan hidup. Dampak tersebut tak terkecuali negara Indonesia, setiap sektor kehidupan pun tak luput dari terjangan pandemi ini, tidak hanya pada wilayah kesehatan namum turut serta grafik penuruhan di sektor ekonomi masyarakat juga dunia pendidikan.

Pemerintah dengan giat selalu mengingatkan pola hidup sehat sebagai wujud program pencegahan untuk menekan angka paparan covid-19 dengan menerapkan jaga jarak, menghindari berkumpul, menghindari kerumuman, belajar, bekerja dari rumah, selalu membawa handsanitizer, selalu rajin mencuci tangan dan selalu menggunakan masker. Perkembangan berita per tanggal 26 Januari 2020 total pasien terkonfirmasi terpapar sebanyak 1.012 .350 , pasien sembuh 820.356 dan pasien meninggal dunia 28.468 , untuk provinsi jawa timur pada tanggal yang sama bertambah menjadi 833 pasien covid-19. [1]

Seluruh elemen masyarakat pun telah berpartisipasi di masa yang sulit ini, mulai dari masyarakat dalam ruang lingkup mikro hingga lembaga non-profit, LSM dan ormas. Kondisi ini menjadikan perguruan tinggi khususnya UIN Maulana Malik Ibrahim Malang prihatin sehingga mendesain bentuk KKM (Kuliah Kerja Mahasiswa) berbeda dari sebelumnya, sebagai wujud pengabdian kepada masyarakat. KKM kali ini dinamakan dengan KKM-DR atau Kuliah Kerja Mahasiswa Dari Rumah. Mahsiswa diberikan tugas melaksanakan pengabdian diseputar tempat atau lingkungan mereka berada sehingga dengan menerapkan pola demikian akan turut membantu dalam pencegahan Covid-19 namun tetap dapat melaksanakan pengabdian, namun demikian praktik KKM-DR dalam satu lingkungan terdapat lebih dari satu peserta karena lokasi tempat tinggal mereka berada sama, tetapi berbeda kelompok atau grup. [11].

Dalam pelaksanaan KKM-DR 2020-2021 mengusung tema besar "Moderasi Beragama dan Pencegahan Penularan Covid-19," dua tema yang menjadi bagian dari isu nasional selain pandemi covid-19. Sosialisasi kehidupan moderasi beragama dilaksanakan dibawah Kementrian Agama Republik Indonesia. Seperti yang digagas oleh kementrian agama bahwa moderasi beragama dijadikan sebagai cara pandang dalam seluruh praktik kehidupan beragama bagi seluruh warga negara Indonesia. Penguatan strategi moderasi beragama dilakukan dengan tiga strategi, pertama, sosialisasi gagasan, pengetahuan dan pemahaman tentang apa itu moderasi beragama; kedua, pelembagaan moderasi beragama ke dalam program dan kebijakan yang mengikat dan ketiga, integrasi rumusan moderasi beragama dalam Rencana Pembangunan Jangka Menengah Nasional 2020-2024. [12].

Dengan demikian maka pada kesempatan kali ini penulis sebagai bagian dari pelaksanaan KKM-DR UIN Malang Mengabdi 2020-2021 memberi judul dalam artikel ini yaitu Peningkatan Adaptasi Covid-19 dan Moderasi Beragama (Pengamatan pada Grup 180 KKM-DR UIN Malang).

\section{METODE PENELITIAN}

Metode pendekatan pengabdian pada masyrakat ini menggunakan pola ceramah, pola pemberian informasi, penyuluhan, simulasi dan pelatihan. Menurut Salmiati, dkk sebagaimana dikutip oleh Putu Adi Suprapto, dkk, Metode simulasi dan latihan bentuknya adalah mempraktekkan situasi yang nyata yang akan dihadapi. [2]

Selain itu juga menggunakan metode Paticipatory Rural Apprasial atau pola pendekatan yang memungkinkan masyarakat dapat berbagi, saling meningkatkan dan menganalisa. Penggunaannya memiliki tujuan agar masyarakat dapat mengembangkan dan menganalisa melalui sebuah kegiatan. [3]

Berdasarkan permasalahan yang ditemukan dilapangan pada mitra maka terdapat beberapa tahapan untuk mengatasi permasalahan tersebut:

1. Melakukan pemetaan kebutuhan hal-hal terkait di lapangan dan berkordinasi dengan mitra;

2. Membuat perencanaan berkala berupa jurnal kegiatan harian dan mingguan yang didalamnya terdapat target pelaksanaan dan antisipasi program jika menemui kendala;

3. Melaksanakan sosialisasi yang difasilitasi oleh para peserta dengan melibatkan mitra secara langsung;

4. Membuat media sesuai dengan kebutuhan mitra di lokasi masing-masing peserta;

5. Pemasangan alat peraga bagi program yang berfungsi sebagai penjelas seperti himbauan :

dan

6. Praktik bersama terkait dengan program yang membutuhkan keterampilan lapangan.

Sumber data terdiri atas sumber data primer dan sumber data sekunder. Sumber data primer yakni sumber data utama yang digunakan kali ini terdiri dari jurnal-jurnal penelitian dan media online berpredikat baik sebagai rujukan informasi akurat seperti media resmi pemerintah, selanjutnya ada hasil observasi pada satu wilayah peserta KKM-DR, sedangkan sumber data sekunder yang digunakan seperti buku-buku teori, 
kumpulan essay peserta KKM-DR grup 180 serta kamus. Pengolahan data menggunnakan pola triangulasi, sebuah metode pengolahan dengan pola percampuran data.

Lokasi penelitian tersebar dibeberapa wilayah jawa timur dan di provinsi NTB, namun satu wilayah menjadi dasar observasi selama berlangsungnya KKM-DR ini yakni Desa Bumiaji Kota Batu. Adapun wilayah pelaksanaan KKM-DR Grup 180 diantaranya: Kabupaten Malang, Kabupaten Pasuruan, Kabupaten Blitar, Kota Batu, dan NTB.

\section{HASIL DAN PEMBAHASAN}

Bagian ini menjabarkan hasil dan pembahasan, hasil berisi tentang informasi atau data tempat KKMDR ini berlangsung, sedangkan pembahasan merupakan uraian hasil yang diperoleh.

\section{Sebaran Peserta KKM-DR Grup 180 Beserta Wilayahnya}

Peserta KKM-DR Grup 180 UIN Malang mengabdi terdiri dari 15 orang baik mahasiswa maupun mahasiswi yang tersebar pada lingkungan domisili mereka, terdapat di beberapa wilayah provinsi Jawa Timur dan Nusa Tenggara Barat. Diantara mereka yang berada di provinsi Jawa Timur yaitu:

\begin{tabular}{|l|l|}
\hline No. & \multicolumn{1}{|c|}{ Lokasi } \\
\hline 1 & Desa Dhompo Kab. Pasuruan \\
\hline 2 & Desa Kedawung Kec. Ngeglok Kab. Blitar \\
\hline 3 & Desa Donowarih, Dusun Karangan, Kec. Karangploso, Kab. Malang, (PP Al-Hidayah) \\
\hline 4 & Desa Ngijo, RW. 03, Kec. Karangploso, Kab. Malang \\
\hline 5 & Desa Petungsewu, Kec. DAU, Kab. Malang \\
\hline 6 & Desa Pulosari, Kec. Jambon, Kab. Ponorogo \\
\hline 7 & Desa Pandanarum, Kec. Sutojayan, Kab. Blitar \\
\hline 8 & Desa Pandanmulyo, Kec. Tajinan, Kab. Malang \\
\hline 9 & Desa Bumiaji Kota Batu \\
\hline 10 & Dusun. Kepuh Selatan, Desa Kepuharjo, Kec. Karangploso, Kab. Malang \\
\hline 11 & Dusun. Supiturang, Desa Bocek, Kec. Karangploso, Kab. Malang \\
\hline 12 & Jl. Ngaglik Gg. IV B, RT. 01 RW. 09, Sukun, Kota Malang \\
\hline 13 & Desa Pandanarum, Kec. Sutojayan, Kab. Blitar \\
\hline 14 & Desa Kemloko, Ngeglok Blitar Jawa Timur \\
\hline
\end{tabular}

Tabel 1.1 Peserta KKM-DR G.180

Satu lokasi peserta berada di Nusa Tenggara Barat :

\begin{tabular}{|l|c|}
\hline No. & Lokasi \\
\hline 1 & Kelurahan Kendo, Kec. Raba, Kota Bima, NTB \\
\hline
\end{tabular}

Tabel 1.2 Peserta KKM-DR G.180

Para peserta mengemban misi dari UIN Maulana Malik Ibrahim Malang yang dituangkan dalam empat bentuk aktifitas dengan masing-masing aktifitas memiliki empat program unggulaan serta dilaksanakan dalam bentuk kegiatan yang variatif disesuaikan kondisi sosial lokasi atau lingkungan para peserta KKMDR, diantara aktifitas Kesehatan dengan program Edukasi Pencegahan Covid-19, aktifitas dakwah dengan program moderasi beragama, aktifitas peningkatan ekonomi dengan program pemberdayaan masyarakat dan aktifitas yang disesuaikan dengan kebutuhan lingkungannya.

Secara umum dari beberapa lokasi tersebut tersebar dibeberapa wilayah Jawa Timur dan NTB memiliki permasalahan yang dapat dikatakan hampir sama mengingat karena kondisi pandemi ini merata, berikut sajian data dari sebagian partikular kegiatan yang telah dilaksanakan oleh peserta grup 180, satu diantaranya terekam baik oleh sebuah media elektronik: 


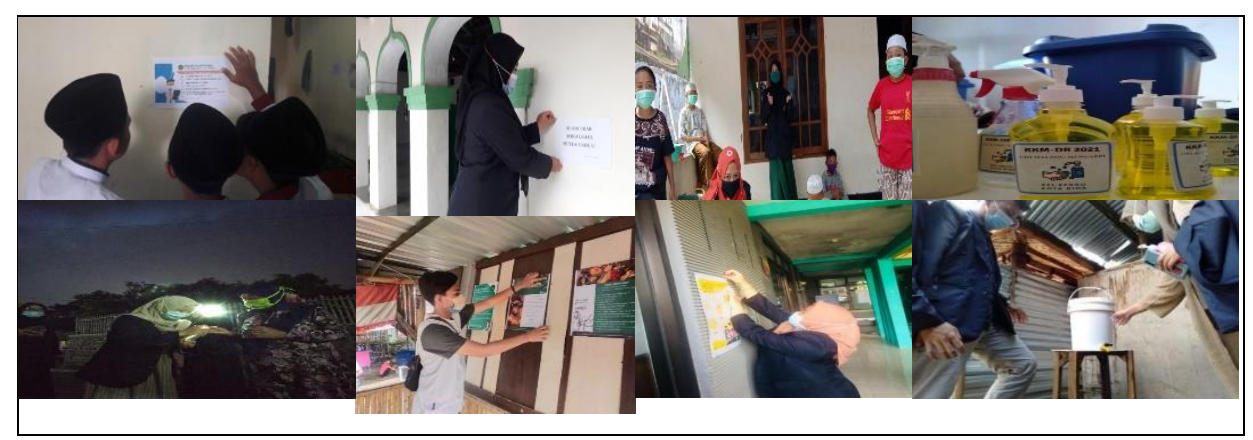

Gambar 1.1 Sosialisasi Pencegahan Covid-19 dan Produk Handsanitizer Sumber: Laporan dan Essay Peserta KKM-DR G. 180

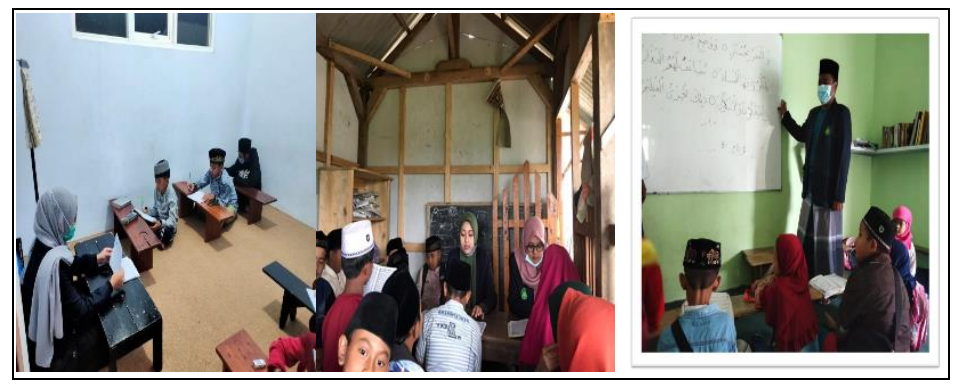

Gambar 1.2 Moderasi Beragama

Sumber: Laporan dan Essay Peserta KKM-DR G. 180

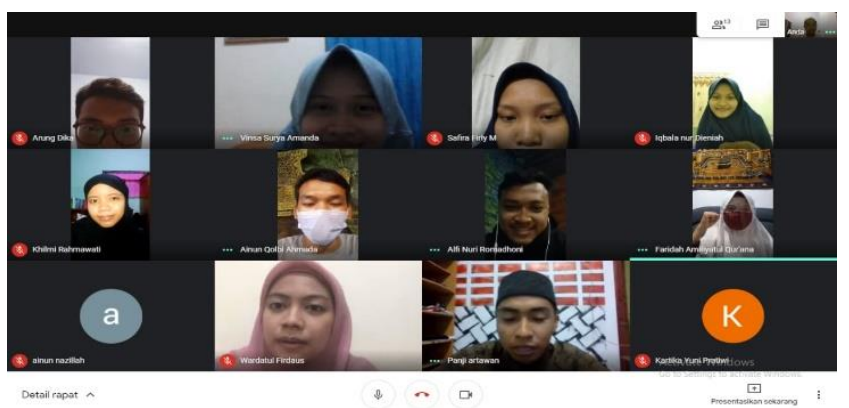

Gambar 1.3 Diskusi Dalam Jaringan Moderasi Beragama Sumber: Laporan dan Essay Peserta KKM-DR G. 180

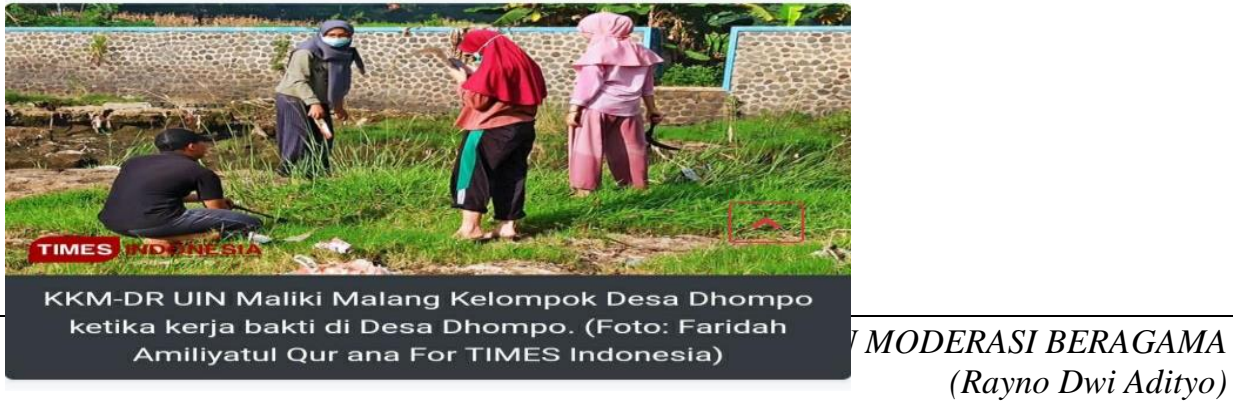



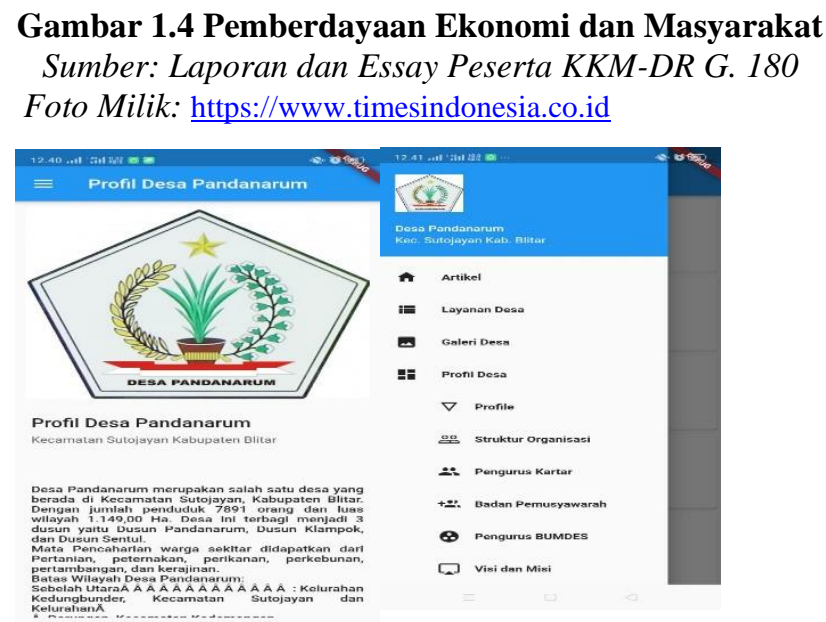

Gambar 1.5 Kebutuhan Masyarakat (Aplikasi Desa berbasis IT) Sumber: Laporan dan Essay Peserta KKM-DR G. 180

\section{Peningkatan Adaptasi Masyarakat Di Tengah Pandemi Dan Sosialisasi Moderasi Beragama}

Adaptif merupakan satu kata yang mensiratkan sikap mampu beradaptasi atau bersifat mudah menyesuaikan diri. [9].

Setiap individu memiliki kemampuan berkomunikasi tergantung pada nilai budaya, norma setempat. Ia akan melakukan adaptasi dengan budaya atau kebiasaan yang berbeda dengannya, agar menjadikan dirinya nyaman. [4]

Ketika setiap individu mampu mengembangkan sikap adaptasi yang baik maka perilakunya pun akan turut berubah kearah yang lebih baik, menurut Geller seperti yang dikutip oleh Nindya Septiani, menjadi penting pendekatan perilaku tersebut berdasarkan atau bertujuan untuk keselamatan. [5]

Semangat dari adaptasi dalam konteks tulisan kali ini yaitu, sisi edukasi yang diberikan oleh peserta kepada masyarakat terbinanya sikap adaptasi terhadap kondisi apapun terlebih saat pandemi covid-19 juga adaptif terhadap sudut pandang moderasi beragama sebagai salah satu agenda dari pemerintah. Agar terciptanya peningkatan adaptasi terhadap kondisi terkini, perlu kiranya dimulai dari menanamkan kebiasaan, contohnya seperti meningkatan budaya membaca, tentu hal ini dimulai dari sebuah kebiasaan. [6]

Terlihat bahwa program secara garis besar yang terlaksana yaitu moderasi beragama, sosialisasi pencegahan covid-19 dan pemberdayaan ekonomi berbasis pemberdayaan masyarakat. Beragama yang moderat (wasathan) merupakan fitrah dari agama Islam merujuk pada firman Allah Swt yang berbunyi: Al-Baqarah: 143).

“.......Dan demikian (pula) kami menjadikan kamu umat yang tengahan (ummatan wasathan)...”.(QS.

Di dalam tafsir Al-Misbah digambarkan bahwa umat Islam merupakan umat yang moderat dan teladan. Posisi pertengahan menempatkan manusia tidak berat ke kiri maupun berat ke kanan, sesuatu hal dimana menjadikan manusia dapat berlaku adil. [10]. Sudah mahfum bahwa Indonesia menjadi sasaran empuk dari paham-paham radikal, mirisnya gerakan-gerakan tersebut telah melakukan penetrasi ke lembaga-lembaga pendidikan, mengapa? karena institusi pendidikan meruakan bagian sentral dari aktifitas penanaman nilai-nilai pembelajaran.

Sehingga pemilihan lembaga pendidikan untuk menanamkan cara pandang beragama yang moderat adalah satu langkah yang cukup efektif dalam menghadang paham inteoleransi[7]. Oleh karenanya dalam pelaksanaan program moderasi beragama peserta KKM-DR UIN Maulana Malik Ibrahim telah tepat memberikan edukasi pada lembaga-lembaga pendidikan tersebut seperti TPQ, pesantren, dan majelis-majelis pengajian dengan menyisipkan pesan-pesan damai yang berdasar nilai-nilai agama. Beberapa catatan misal salah satu peserta memberikan pemahaman bahwa perbedaan dalam Islam itu merupakan keniscayaan, sehingga harapannya dalam ruang lingkup kecil untuk umat Islam sendiri dapat menghormati satu sama lain tidak saling mencela, adapula yang berbentuk diskursus dengan platform daring atau virtual, selain bertujuan untuk memberikan pemahaman tentang moderasi namun juga sebagai wujud partisipasi program pemerintah dengan menghindari kerumunan. 
Selanjutnya sosialisasi tentang pencegahan penularan covid-19 tak lupa selalu dilaksanakan ditingkat manapun baik ketika beraktiftas di masyarakat, lembaga pendidikan dan rumah ibadah. Bentuknya pun beragam, mulai dari sosialisasi hidup sehat seperti mencuci tangan, membawa handsanitizer, menjaga jarak, membawa masker dan protokol lainnya, adapula yang melaksanakan kegiatan dengan membuat handsanitizer mandiri dari bahan-bahan sekitar warga yang mudah ditemukan, ada pula yang menyebarkan flayer, spanduk ataupun poster-poster di ruang publik wilayahnya masing-masing. Semua merupakan bentuk upaya untuk mendorong masyarakat sekitar mampu beradaptasi, dengan adanya pandemi covid-19 ini memaksa kebiasaan kita setiap lininya berubah.

Keberhasilan dari peserta juga nampak pada peserta lainnya, ditengah pusaran pandemi mereka mampu menghasilkan karya dalam bentuk pemberdayaan masyarakat, dan bakti sosial. Satu diantaranya karya berupa aplikasi desa yang berbasis informasi teknologi sebagai pusat informasi terkait desa dari aspek apapun, lalu yang menarik selain itu sebagaimana yang dilansir oleh timesindonesia.co.id, ada peserta yang mencoba untuk menghidupkan kembali wisata lokal tepatnya di desa Dhompo kabupaten Pasuruan. [8]

Diharapkan dengan dibuka kembali lokasi wisata tersebut dapat turut membantu meningkatkan perekonomian masyarakat sekitar.

\section{KESIMPULAN}

Setiap kegiatan yang dilakukan oleh para peserta KKM-DR grup 180 paling tidak telah sedikit banyak memenuhi dari target yang dicanangkan UIN Maulana Malik Ibrahim Malang tahun 2021 dimana terdiri dari empat program besar yakni moderasi berama, pencegahan covid-19, pemberdayaan ekonomi dan pelayanan publik sesuai kebutuhan maysarakat lingkungan sekitar, hanya saja program keempat, peserta KKM-DR grup 180 sedikit yang tercapai dalam pelaksanaannya. Program yang terlaksana didominasi dari moderasi beragama, pencegahan covid-19 dan pemberdayaan masyarakat.

Program moderasi beragama banyak dilaksanakan di lingkungan pendidikan walaupun ada pula yang mendesain edukasi tentang moderasi beragama secara daring dengan wujud kelompok diskusi, kegiatan moderas beragama salah satunya dengan menyisipkan pesan-pesan cara pandang beragama yang moderat dan damai.

Program pencegahan covid-19, semua peserta melaksanakan dengan beragam bentuk kegiatan mulai dari penyebaran pamlet, flyer, spanduk, sosialisasi seperti penyuluhan yang kontennya seputar himbauan menjaga jarak, menggunakan masker, menghindari kerumunan, pembuatan handsanitaizer dan hal-hal yang berkaitan dengan protokol kesehatan.

Program pemberdayaan masyarakat dan bakti sosial ada yang menarik diantaranya, menghidupkan kembali sebuah kawasan wisata lokal di salah satu desa kabupaten Pasuruan dan pembuatan aplikasi desa berbasis teknologi informasi.

Semua kegiatan dimaksudkan untuk mendorong masyarakat lingkungan sekitar tempat tinggalnya mampu beradaptasi dengan kondisi dan kebiasaan baru serta merubah pola perilaku kesehariannya demi tercapainya keselamatan dan kemajuan bersama.

\section{UCAPAN TERIMAKASIH}

Ucapan terimakasih penulis sampaikan untuk Rektor UIN Maulana Malik Ibrahim beserta jajarannya dan juga LP2M serta panitia KKM-DR periode 2020-2021 atas pendampingannya meliputi kesempatan yang diberikan kepada peserta adik-adik mahasiswa/wi KKM-DR ini. Rasa terimakasih pula kami haturkan kepada para mitra baik perangkat desa, perangkat RT dan RW, serta perangkat kelurahan KKM-DR 2021 pada masingmasing lokasi dan kecamatan karena atas perkenaannya, penerimaannyalah seluruh kegiatan dapat terlaksana dengan baik dan lancar.

\section{DAFTAR PUSTAKA}

“Agenda | Covid19.go.id.” https://covid19.go.id/agenda/2021/january (accessed Mar. 31, 2021).

[2] P. A. Suprapto et al., "PEMBERDAYAAN BADAN USAHA MILIK DESA PANCA SARI AMERTA, DESA SINGAPADU KALER,” Dec. 2020. Accessed: Mar. 31, 2021. [Online]. Available: http://jurnal.unpad.ac.id/dharmakarya/article/view/30329. 
[3] I. Darmawan, "PENINGKATAN KESADARAN AKAN PENGELOLAAN SAMPAH DI DESA CINTA MULYA MELALUI WORKSHOP INTEGRATIF DAN KREATIF,” Dharmakarya, vol. 9, no. 4, p. 249, Dec. 2020, doi: 10.24198/dharmakarya.v9i4.26624.

[4] L. Savitri and S. Utami, “Teori-Teori Adaptasi Antar Budaya,” Dec. 2016. Accessed: Mar. 31, 2021. [Online]. Available: https://journal.untar.ac.id/index.php/komunikasi/article/view/17.

[5] N. Septiani, "BEBERAPA FAKTOR YANG BERHUBUNGAN DENGAN PERILAKU PEKERJA DALAM PENERAPAN SAFE BEHAVIOR DI PT. HANIL JAYA STEEL,” Indones. J. Occup. Saf. Heal., vol. 6, no. 2, p. 257, Mar. 2018, doi: 10.20473/ijosh.v6i2.2017.257-267.

[6] V. T. Handayani, A. Afsari, and F. Hasanah, "DONGENG SEBAGAI STIMULAN AWAL PENINGKATAN MINAT BACA BAGI SISWA PAUD BUNDA HAJAR JATINANGOR,” Sep. 2018. Accessed: Mar. 31, 2021. [Online]. Available: http://jurnal.unpad.ac.id/pkm/article/view/20341.

[7] E. Prasetiawati, "Menanamkan Islam Moderat Upaya Menanggulangi Radikalisme di Indonesia," Fikri J. Kaji. Agama, Sos. dan Budaya, vol. 2, no. 2, pp. 2527-4430, Dec. 2017, doi: 10.25217/jf.v2i2.152.

[8] "KKM-DR UIN Maliki Malang Hidupkan Kembali Wisata Dam Licin di Pasuruan | TIMES Indonesia." https://www.timesindonesia.co.id/read/news/322753/kkmdr-uin-maliki-malanghidupkan-kembali-wisata-dam-licin-di-pasuruan (accessed Mar. 31, 2021).

[9] Al-Barry, M. D. Kamus Modern Bahasa Indonesia.1994. Yogyakarta: Arkola.

[10] Shihab, Q. M. Tafsir Al-Mishbah Vol 1 Pesan, Kesan, dan Keserasian dalam Al-Qur'an, 2016.Jakarta. Lentera Hati.

[11] Panduan KKM-DR UIN Mengabdi 2020-2021. Moderasi Beragama dan Pencegahan Penularan covid-19.2020. Malang. LP2M UIN Maulana Malik Ibrahim.

[12] Kementrian Agama. Moderasi Beragama. 2019.Jakarta. Balitbang Kemenag. 